\title{
Processing of Graphite-Based Sacrificial Layer for Microfabrication of Low Temperature Co-fired Ceramics (LTCC)
}

\author{
Hansu Birol, Thomas Maeder, Peter Ryser \\ Laboratoire de Production Microtechnique, Ecole Polytechnique Fédérale de Lausanne, Station 17, CH-1015 Lausanne, \\ Switzerland.
}

Version of record: Birol-H Maeder-T Ryser-P, "Processing of graphite-based sacrificial layer for microfabrication of low temperature co-fired ceramics (LTCC)", Sensors and Actuators A 130-131, 560-567, 2006.

http://hdl.handle.net/10.1016/j.sna.2005.12.009

\begin{abstract}
The processing and application of graphite powder-based sacrificial layer for fabrication of microfluidic structures in LTCC is described. Such layers are produced as pastes, which are screen-printed in LTCC sheets to avoid sagging, by supporting closed, three-dimensional structures such as channels, membranes during firing. The aim of the paper is to highlight the selection of paste materials and the effects of processing conditions on the fabricated micro-fluidic components. It is seen that the complete burnout of graphite powder is the most critical stage as it is in kinetic competition with the open pore-elimination process of LTCC, which occurs at $785^{\circ} \mathrm{C}$ in our system.
\end{abstract}

Keywords: LTCC, fabrication of microfluidic structures, sacrificial layer, permeability of LTCC.

\section{Introduction}

LTCC technology is based on LTCC tapes, which are cast from slurries of ceramic-filled glass systems those mixed with an organic vehicle [1-3]. They are produced by commercial suppliers at different thicknesses [4] varying from 30 to $350 \mu \mathrm{m}$. Low temperature and co-fired terms refer to firing temperatures below $900^{\circ} \mathrm{C}$ and simultaneous firing of LTCC tape and thick-film pastes of electronic components, respectively [1-3]. Both of these keywords signify various benefits in microsystems engineering. In addition to processing feasibility, low firing temperatures permit the utilization of conductors with low resistances such as $\mathrm{Au}, \mathrm{Ag}, \mathrm{Ag} / \mathrm{Pd}$, which have low melting temperatures and can ideally be fired below $900^{\circ} \mathrm{C}[5]$. On the other hand these thick-films can be screen-printed and fired on LTCC substrates, which have low dielectric constants $(\mathrm{K})$, creating an ideal platform for high-speed signal circuitry due to low losses [6]. Consequently, the technology has been used for long years in telecommunication sector for highfrequency applications and/or for highly reliable electronic army components $[3,7,8]$. Recently, applications in sensorics and microfluidics, which originate from other interesting properties of LTCC technology, have been demonstrated [8-11]. Thermal and chemical stability of LTCC tapes, high-packaging density with increased functionality capability, high yield-low cost production possibility in industry, combination of electrical and mechanical functions in a hermetic system can be counted as other attractive features.

However all of these different applications benefit from one great advantage of this technology, which is the ease of utilization of LTCC tapes. They can be cut by laser, punched, screen-printed with a large variety of conductors and passive electronic components, and then laminated up to 80 layers. This provides considerable flexibility in device fabrication.

For microfluidics, one additionally needs the ability to create controlled voids in order to fabricate structures such as membranes and channels. To this end, this paper aims to introduce a sacrificial paste, which is based on graphite-powder, to support the closed, three-dimensional, microfluidic components 
during firing. The selection of the paste materials, their characterization, and effects of processing conditions will be explained in details. Moreover a recently developed closed-chamber system for permeability analysis of the LTCC substrates will be presented. Finally the fabricated structures will be demonstrated in relation to the processing conditions. The methods of the study will be thermogravimetric (TGA) and dilatometry analysis, scanning electron microscopy (SEM) and electronic systems to measure the permeability of the LTCC substrates.

\section{Preparation of Sacrificial Pastes}

There are different methods to prevent deformation of LTCC structures during firing [12]. These can be classified as passive and active methods, which are based on manipulation of lamination conditions and utilization of sacrificial layers (graphite powder, fugitive phases, etc.), respectively. Although the common aim is the reduction of deformation, which is mostly observed as sagging, delamination, etc., (figure 1), the selection depends on the specifications and acceptable tolerances of the desired device. From this paper's point of view, the latter choice has become the ideal approach since fabrication of microfluidic components require full integrity and well-defined dimensions free of deformation.

On the other hand the motivation for selection of graphite powder-based paste is primarily due to its easy burnout, which ideally occurs according to equation 1 . Thus, the paste supports the three-dimensional structure up to the burnout temperature of graphite powder, which is followed by gas removal and further densification of the LTCC tape.

$$
\mathrm{C}(\mathrm{s})+\mathrm{O}_{2}(\mathrm{~g}) \rightarrow \mathrm{CO}_{2}(\mathrm{~g})
$$

Secondly, the paste can be screen-printed, which facilitates fine and easy structuring of desired patterns. Additionally it does not interact with the LTCC tape during firing.

We prepared the pastes in a similar fashion to those in thick-film technology: the functional material was blended with the organic vehicle in order to retain sufficient rheology for screen-printing. In our case, two types of graphite powder, which vary in particle size, were used as the functional element. From here on we will be referring to fine $(2 \mu \mathrm{m})$ and coarse $(15 \mu \mathrm{m})$ graphite powders as FG and CG, respectively, both of which were processed by the same procedure. This is to say the powder was initially blended with the previously-prepared mixture of binder (ethylcellulose) and solvent (terpineol), which was then followed by addition of dispersant (acetyl acetone) to increase the efficiency of mixing. The overall suspension was finally homogenized on a three-roll mill. The exact compositions by weight of the prepared pastes can be seen in table 1.

Pastes based on FG and CG were then screen-printed according to the layout shown in figure 2, which has the large central area and inlet and outlet channels. The printed tapes (DuPont 951-AX) were dried for 10 minutes in air and at $120^{\circ} \mathrm{C}$, respectively. Lamination with thinner LTCC tapes (DuPont 951-C2), which was intended for improved device functionality (pressure sensing, reduced thermal dissipation) was carried out at $70^{\circ} \mathrm{C}$ under $25 \mathrm{MPa}$. Finally the structures were fired according to a two-step firing profile in an LTCC oven (ATV-PEO 601). Samples were heated at a rate of $5^{\circ} \mathrm{C} / \mathrm{min}$ and kept at $440^{\circ} \mathrm{C}$ for organic burnout of the tape. This step was followed by heating the samples at the same rate up to the peak firing temperature of $875^{\circ} \mathrm{C}$ (peak dwell time of 25 minutes). 


\section{Results}

The most important material properties and processing parameters, which directly influenced the fabricated membranes, can be summed as the chemistry and the particle size of the graphite powder used, heating rate, diameter of the membrane and the thickness of the overall module (number of thicker LTCC layers). Figure 3 shows the membrane cross-section of a $7 \mathrm{~mm}$-diameter membrane, which was prepared by FGbased sacrificial paste. It is seen that the membrane has well-defined spacing of approximately $13 \mu \mathrm{m}$ free of deformation. Moreover the layers at the edge are fully integrated.

Although sagging and delamination was avoided in all membranes, a new type of defect was observed in those prepared with CG-based sacrificial paste. It was basically the swollen membrane surface, the extent of which was primarily dependent on the heating rate and also the diameter of the membrane (amount of paste printed). In order to analyze the situation, we primarily checked the membrane flatness by increasing membrane diameter at fixed heating rate $\left(5^{\circ} \mathrm{C} / \mathrm{min}\right)$. The surface profiles, which are shown in figure 4 , were plotted by laser-equipped profilometer that is frequently used to measure the thickness of printed films. The $y$-axis indicates the height of the points scanned on the surface relative to the calibrated values, whereas the $\mathrm{x}$-axis is the trajectory over the membrane. It was clearly seen that the initially-flat membrane got swollen upon increased diameter. Macroscopic and microscopic (by SEM) images show the difference between 7 and $14 \mathrm{~mm}$-diameter membranes in figure 5.

Similar to the effect of larger membranes, heating also increased the membrane deflection at higher rates. Figure 6 shows the effect of increased heating rates from $3.5^{\circ} \mathrm{C} / \mathrm{min}$ to $5^{\circ} \mathrm{C} / \mathrm{min}$ for the same membrane size ( $9.5 \mathrm{~mm}$-diameter).

To sum up, the membranes prepared with CG-based pastes had dependency on the membrane diameter (amount of paste deposited) and the heating rate compared to the FG-based one. Increase of these parameters resulted in swollen membranes, which should be avoided for fully functional devices. Thus, the next section focuses on basic understanding of these results in terms of materials properties, which are directly influenced by the discussed processing conditions.

\section{Discussions}

Although FG-based paste was efficiently used without resulting in any defects, it was insufficient in supporting large membranes with diameters of 14 and $18 \mathrm{~mm}$. This was due to locally sagged membrane at different locations. The use of paste with CG allowed to solve this problem and to attain larger spacings if desired. To investigate the origin of the difference between FG and CG, we checked the related properties of the materials used: the burnout characteristics of the graphite powders and the densification behavior of LTCC tape. These analyses were made using TGA and dilatometry respectively.

Figure 7 shows the TGA of the FG and CG carried out in air atmosphere, indicating the remaining percentage of both powders as a function of temperature. One can directly see the different burnout kinetics of the powders. Complete burnout of FG and CG is achieved around $770^{\circ} \mathrm{C}$ and $865^{\circ} \mathrm{C}$ respectively. This latter value is close to the firing temperature of the whole LTCC module $\left(875^{\circ} \mathrm{C}\right)$. Apart from graphite, LTCC permeability was also controlled since the fabrication method introduced suggests the removal of the gas product (equation 1) through the porous LTCC. In order to confirm this, we conducted dilatometry analysis to detect the onset temperature for densification of LTCC substrate. Dilatometry experiment was made on LTCC pellets, which were prepared by dissolving the tape in acetone and separating the powder that was finally pressed. Figure 8 shows the densification behavior of the LTCC material. The graphic demonstrates that the onset of shrinkage is at $670^{\circ} \mathrm{C}$ and $33 \%$ of the total tape shrinkage (total shrinkage around $15 \%$ ) is finished at the burnout temperature of $\mathrm{FG}$.

However this information was still far from being precise in order to find the exact open pore-elimination temperature from the LTCC. Thus we developed a closed-chamber system to determine this temperature, which is of highest importance as gases produced after this temperature would be entrapped in the nonpermeable LTCC structure. According to the system we built (figure 9), the LTCC substrates fired at 
different temperatures were inserted between two O-rings and the pressure was applied via the piston. The system detects open porosity qualitatively via the relaxation time of the pressure drop, which was measured by the pressure sensor.

The firing temperature selection of the substrates, which were used for permeability measurements, was basically inspired by the cross-sectional SEM images of buried samples from an on-going study. The buried samples, which were swollen at the LTCC tape-conductor-resistor interface in a similar way to the membranes, are illustrated in figure 10. According to these images, onset of swelling, which occurs due to open porosity elimination of LTCC, occurs in the $775-800^{\circ} \mathrm{C}$ range. Thus we used the LTCC substrates, which were fired at $750,775,780$ and $785^{\circ} \mathrm{C}$. The results obtained can be seen in figure 11 . The results demonstrate that, the applied pressure drops instantly on substrates fired at $750^{\circ} \mathrm{C}$ (figure 11 , graph on the left), which indicates the existence of open porosity at this temperature. On the other hand, substrates fired at 775 and $780^{\circ} \mathrm{C}$ addressed an intermediate regime, as a result of onset of open porosity-elimination, which, however still exhibited certain permeability. It is clearly seen from the linear behavior of pressure change in the second graph that LTCC was no more permeable at $785^{\circ} \mathrm{C}$. The slight drop in the pressure value at this temperature can be neglected as the substrates fired up to $900^{\circ} \mathrm{C}$ resulted in the same behavior.

In light of these results, the reason of swelling in membranes those fabricated using CG-based sacrificial paste, is ascribed to the burnout characteristics of the powder. It is observed that any gas producing reaction following the closure of open porosity on LTCC $\left(785^{\circ} \mathrm{C}\right)$ results in swelling. In case of FG, the reaction is completed prior to the open porosity elimination temperature, as a result of which flat membranes are obtained. However the burnout of CG goes up to $865^{\circ} \mathrm{C}$, which results in entrapment of the gas products evolved after $785^{\circ} \mathrm{C}$. Although the oxidation of CG continues due to the limited entry of air via the inlet and outlet channels, this depleted amount, together with the rising temperature, is believed to shift the $\mathrm{CO} / \mathrm{CO} 2$ balance according to:

$$
\mathrm{C}(\mathrm{s})+\mathrm{CO} 2(\mathrm{~g}) \rightarrow 2 \mathrm{CO}(\mathrm{g})
$$

which increases the pressure inside the membrane and causes swelling.

In spite of this limitation, it was possible to fabricate large, flat membranes (figure 12) using CG-based sacrificial paste, which required optimization of heating rate $\left(3^{\circ} \mathrm{C} / \mathrm{min}\right)$, membrane size and material properties simultaneously. Finally figure 13 shows a fabricated microfluidic device based on the proposed method, which is post-fired with terminations and thick-film resistors (TFR).

\section{Conclusion}

Utilization of graphite-based sacrificial paste for fabrication of LTCC microfluidic components was described. Basic material and processing parameters were investigated and the fabricated structures were evaluated in terms of their effects. Membrane specifications were found to depend strongly on the kinetic competition between the burnout characteristics of the graphite powders used and the LTCC open porosityelimination process. Flat, small membranes (up to $10 \mathrm{~mm}$ diameter) were easily fabricated using the finesized powders, whereas larger membranes showed dependency on additional parameters such as heating rate and membrane size (diameter). This was linked to the retarded burnout of the coarser powder, which occurred approximately $90^{\circ} \mathrm{C}$ above the LTCC open-porosity elimination temperature, which was determined to lie around $785^{\circ} \mathrm{C}$. Depletion of air to oxidize the graphite over this temperature and lack of degassing resulted in formation of entrapped gas in these samples, which lead to swelling. In this case, flatness was achieved by optimization of the heating rate for the membrane size in consideration, achieving a balance between formation of gas inside the membrane by oxidation of the graphite and its evacuation through the LTCC and the channels. 


\section{References}

[1] H. Jantunen, A novel low temperature co-firing ceramic (LTCC) material for telecommunication devices, PhD. Thesis, University of Oulu, Finland, 2001.

[2] M. Eberstein and W.A. Schiller, Development of high-permittivity glasses for microwave LTCC tapes, Glass Sci. Technol., Vol. 76 (1), 2003, pp. 816.

[3] S. Nishigaki and J. Fukuta, Low temperature, cofirable, multilayered ceramics bearing pure Ag conductors and their sintering behavior, Adv. Ceram., Vol. 26, 1989, pp. 199215.

[4] M. Jackson, M. Pecht, S.B. Lee and P. Sandborn, Integral, embedded and buroed technologies, Calce Electronics and Products Centre Archive, 2003.

[5] S.X. Dai, R.F. Huang and D.L. Wilcox, Sr., Temperature stable, low loss and low fire dielectrics for consumer wireless applications, Proceedings, 1st China International Conference on High Performance Ceramics, 1998, pp. 338341.

[6] J.H. Jean and C.R. Chang, Cofiring kinetics of an Ag-metallized ceramic-filled glass electronic package, J. Am. Ceram. Soc., Vol. 80 (12), 1997, pp. 30843092.

[7] C.S. Hsi and M.W. Lee, Properties of tuthenium-based resistors embedded in low-temperature co-firable ceramic substrates, Jpn. J. Appl. Phys.., Vol. 41, 2002, pp. 53235328.

[8] Y.S. Cho, K.W. Hang, M.F. Barker, P.J. Olliver, C.B. Wang, D. I. Amey, K. Souders and C.R. Needes, New $\mathrm{Pb}$-free LTCC systems for auto and telecommunication applications, Proceedings, IMAPS Conference and Exhibition on Ceramic Interconnect Technologies, Denver, 2004, pp. 226230.

[9] M.G. Rubio, L.S: Laguna, P.J. Moffet and J.J.S. Aviles, The utilization of LTCC-ML technology for mesoscale EMS, a simple thermistor-based flow sensor, Sensor Actuat. A Phys., Vol. 73, 1999, pp. 215221.

[10] T. Thelemann, H. Thust and M. Hintz, Using LTCC for microstystems, Proceedings, European Microelectronics Packaging and Interconnection Symposium, Cracow, 2002, pp. 187-191.

[11] L.J. Golonka, B.W. Licznerski, K. Niitsch, H. Teterycz, R. Bauer and K.J. Wolter, Example of gas sensors by application of thick film technology, Proceedings, 43rd International Sci. Colloq., TU Illmenau, Illmenau, 1998, pp. 465470.

[12] P.E. Vallejoz, J. Zhong, M.G. Rubio, L.S. Laguna and S.S. Aviles, Meso (intermediate) - scale electromechanical systems for the measurement and control of sagging in LTCC structures, Mat. Res. Soc. Symp. Proc., Vol. 518, 1998, pp. 7379.

\section{Biographies}

Hansu Birol received his BSc degree in materials science and engineering from Middle East Technical University, Ankara, Turkey in 1999 and MSc degree in sensor systems and technologies from Karlsruhe University of Applied Sciences, Germany in 2001. Currently he is doing his PhD at Swiss Federal Institute of Technology, EPFL, Switzerland, at the Microengineering Department. His current research interests are optimization of physical and chemical materials incompatibilities within low temperature co-fired ceramics (LTCC) system and fabrication of LTCC-based microfluidic devices for sensor applications.

Thomas Maeder pursued with a PhD in piezoelectric thin films, and a post-doc at IBM Rüschlikon in single-crystal conductive oxides, after graduating from the École Polytechnique Fédérale de Lausanne (EPFL) in materials science. He now heads the thick-film technology group at the EPFL, where current areas of interest are thick-film and LTCC technology for advanced sensor and packaging applications, and sensor networking.

Peter Ryser, Swiss citizen, received a Master degree in physics (University Neuchâtel 1979), a PhD in applied physics (University Geneva 1985) and a Masters Degree in corporate management (Lucerne 1993). His professional background includes several R\&D activities. From 1990 to 1998 he was the head of research at Siemens Building Technologies. Since 1999 Peter Ryser is professor at the Swiss Federal Institute of Technology EPFL in Lausanne and act as a director for the micro engineering section. 
Table 1. Composition of prepared pastes by weight percent

\begin{tabular}{|c|c|c|c|c|c|}
\hline Powder & $\mathbf{d}_{\mathbf{5 0}}(\boldsymbol{\mu m})^{*}$ & Graphite & Binder & Solvent & Dispersant \\
\hline FG & 2 & 27.4 & 3.1 & 64 & 5.5 \\
\hline CG & 15 & 25.8 & 2.7 & 69.2 & 2.3 \\
\hline
\end{tabular}

$\left(^{*}\right)$ : Particle size of the powder
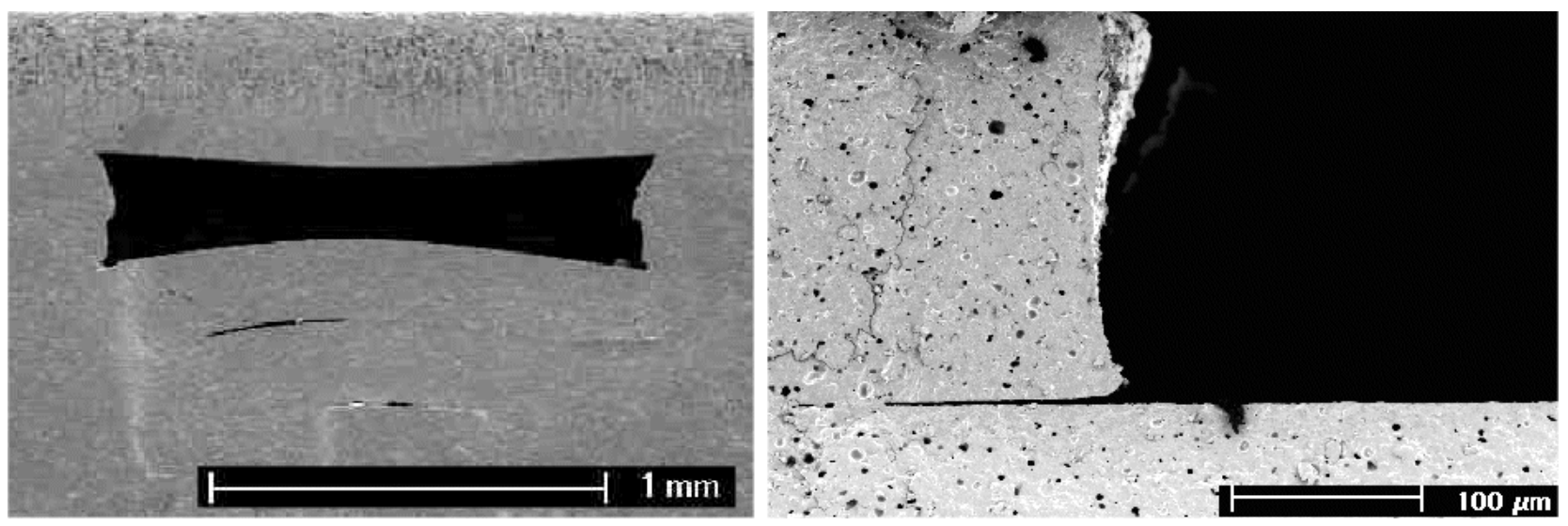

Figure 1. Sagging (left) and delamination of unsupported samples during firing.

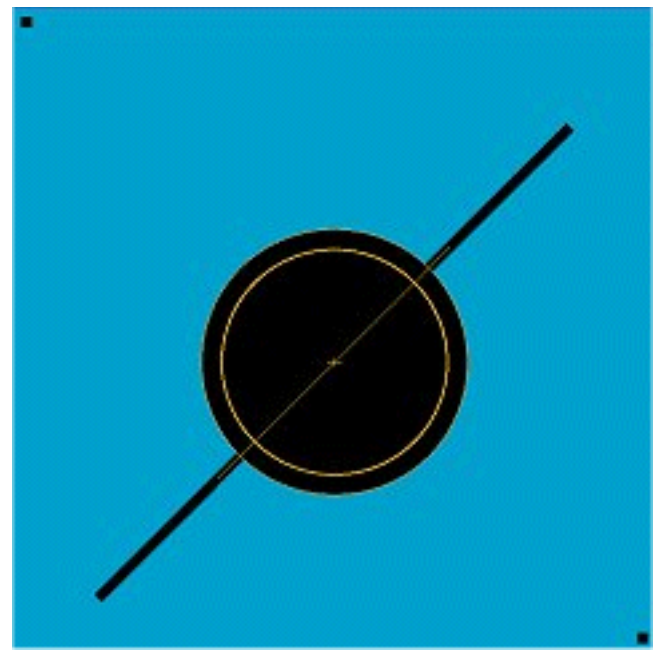

Figure 2. Layout for the membrane of the microfluidic device. 

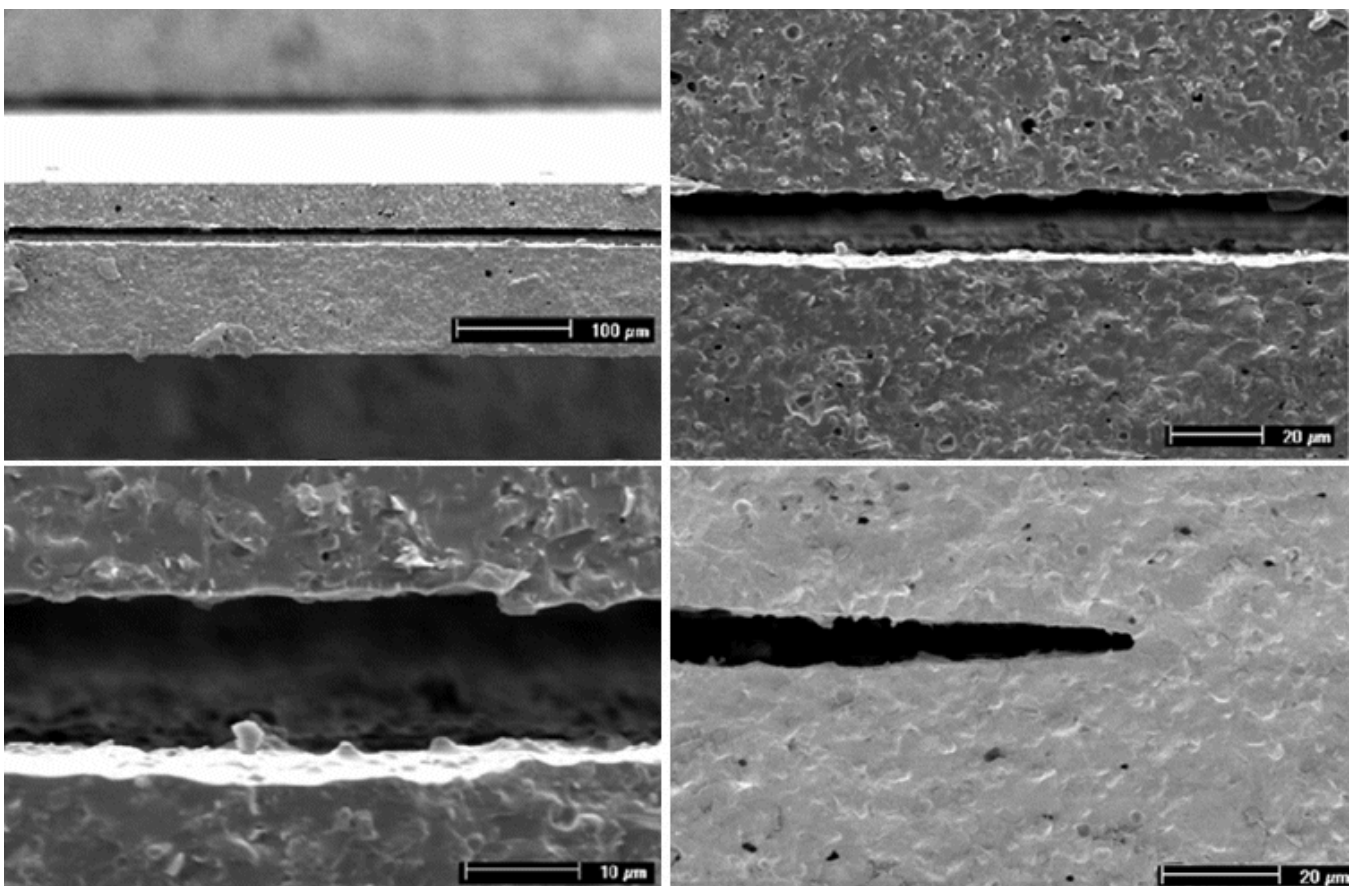

Figure 3. $7 \mathrm{~mm}$-diameter fabricated using FG-based paste. A uniform, 13 $\mu \mathrm{m}$-spacing is obtained free of deformation and with full integration of layers (right below).
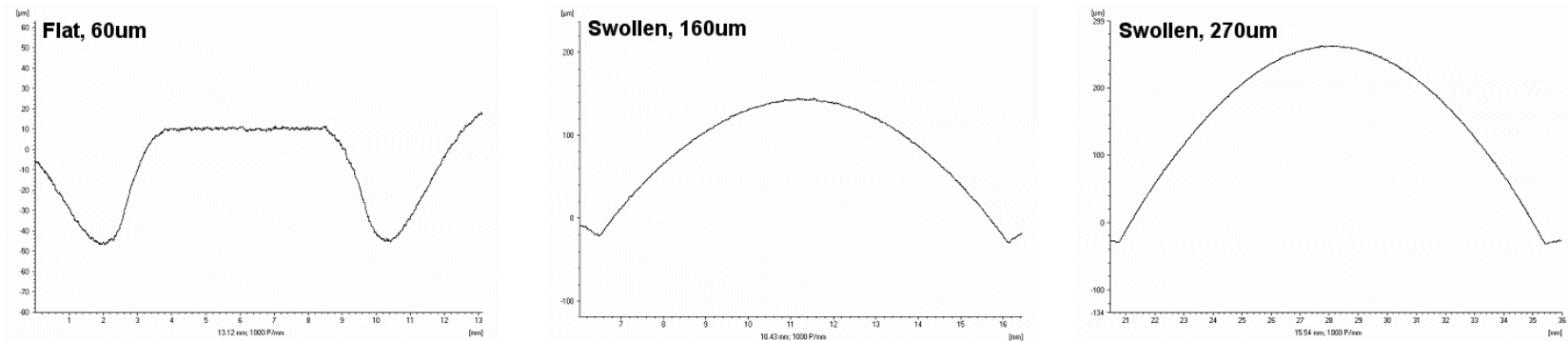

Figure 4. 7 (far left), 9.5, 14mm-diameter membranes fabricated using CG-based sacrificial paste (note that the y-axis have different scales).

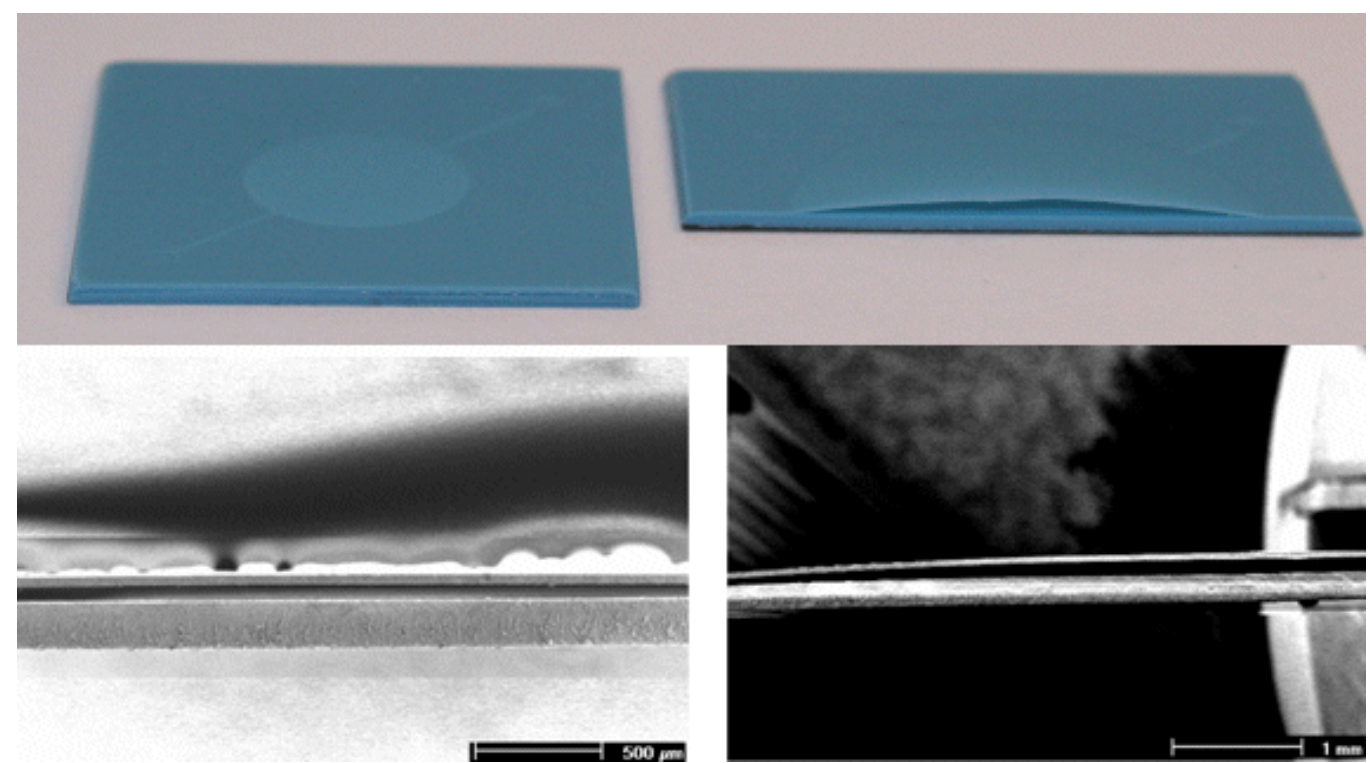

Figure 5. Optical and microscopic (by SEM) images of flat, $7 \mathrm{~mm}$ (left top and left bottom) and swollen, $14 \mathrm{~mm}$ diameter membranes. 

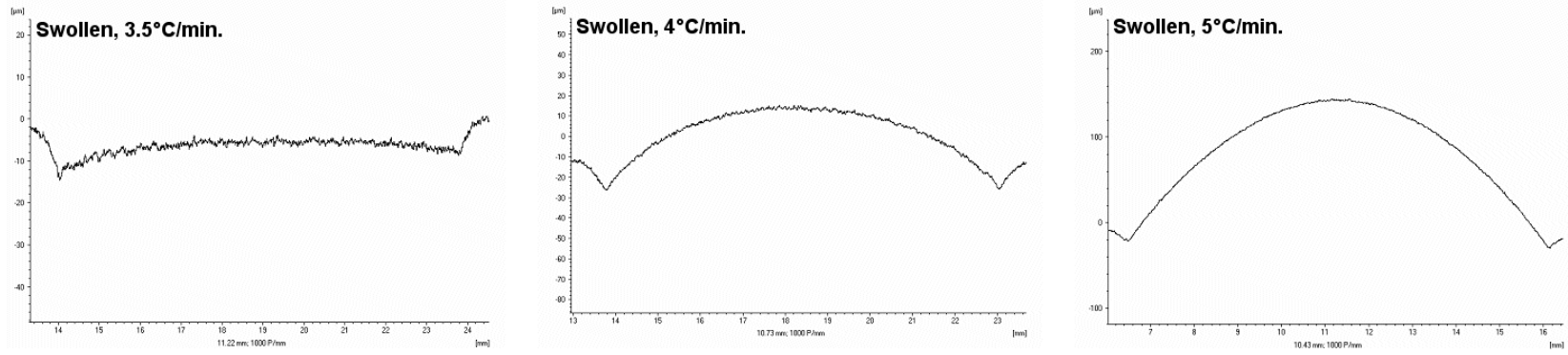

Figure 6. Surface profiles of $9.5 \mathrm{~mm}$-diameter membranes up on increased heating rate (note that the y-axis have different scales).

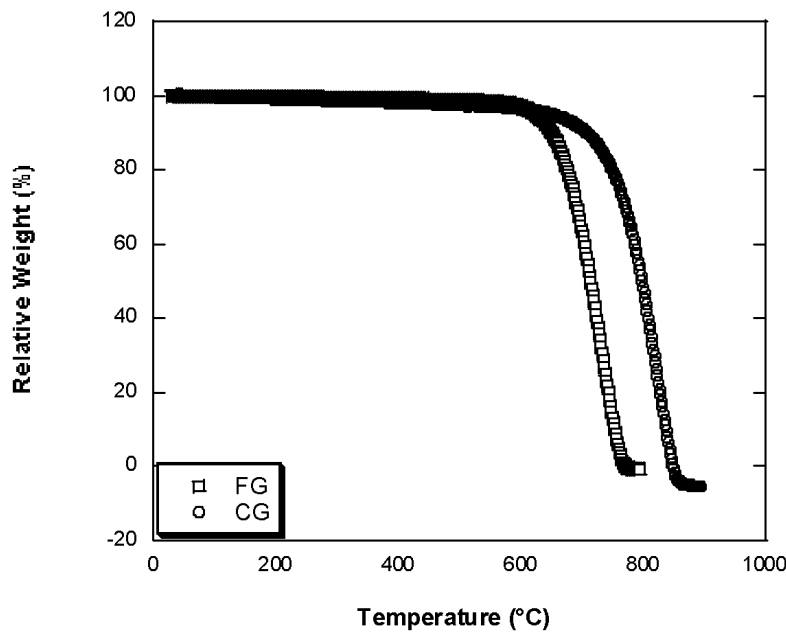

Figure 7. Comparison of burnout characteristics of graphite powders by TGA (heating rate: $10^{\circ} \mathrm{C} / \mathrm{min}$ ).

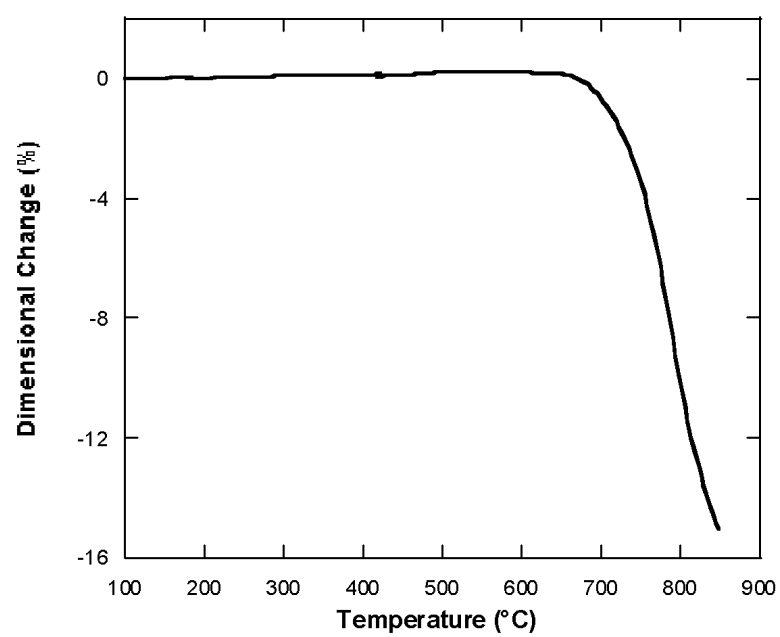

Figure 8. Densification behavior of the pellet prepared from the LTCC tape.

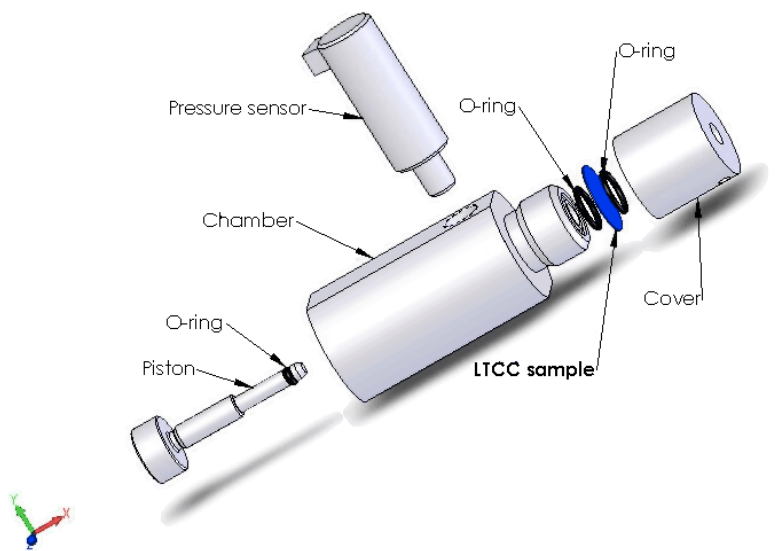

Figure 9. Closed-chamber to detect the open-porosity elimination temperature of LTCC. 

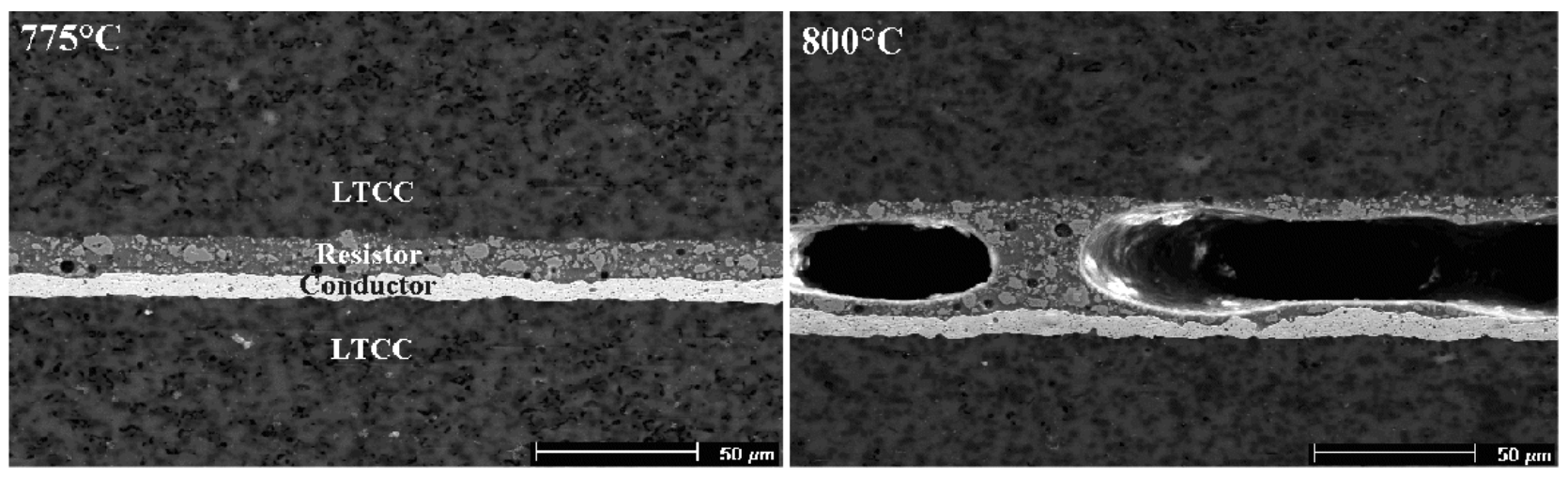

Figure 10. Closure of LTCC open-porosity estimated to occur between $775^{\circ} \mathrm{C}$ (left) and $800^{\circ} \mathrm{C}$, approved by the cross-sectional SEM images of buried LTCC components.
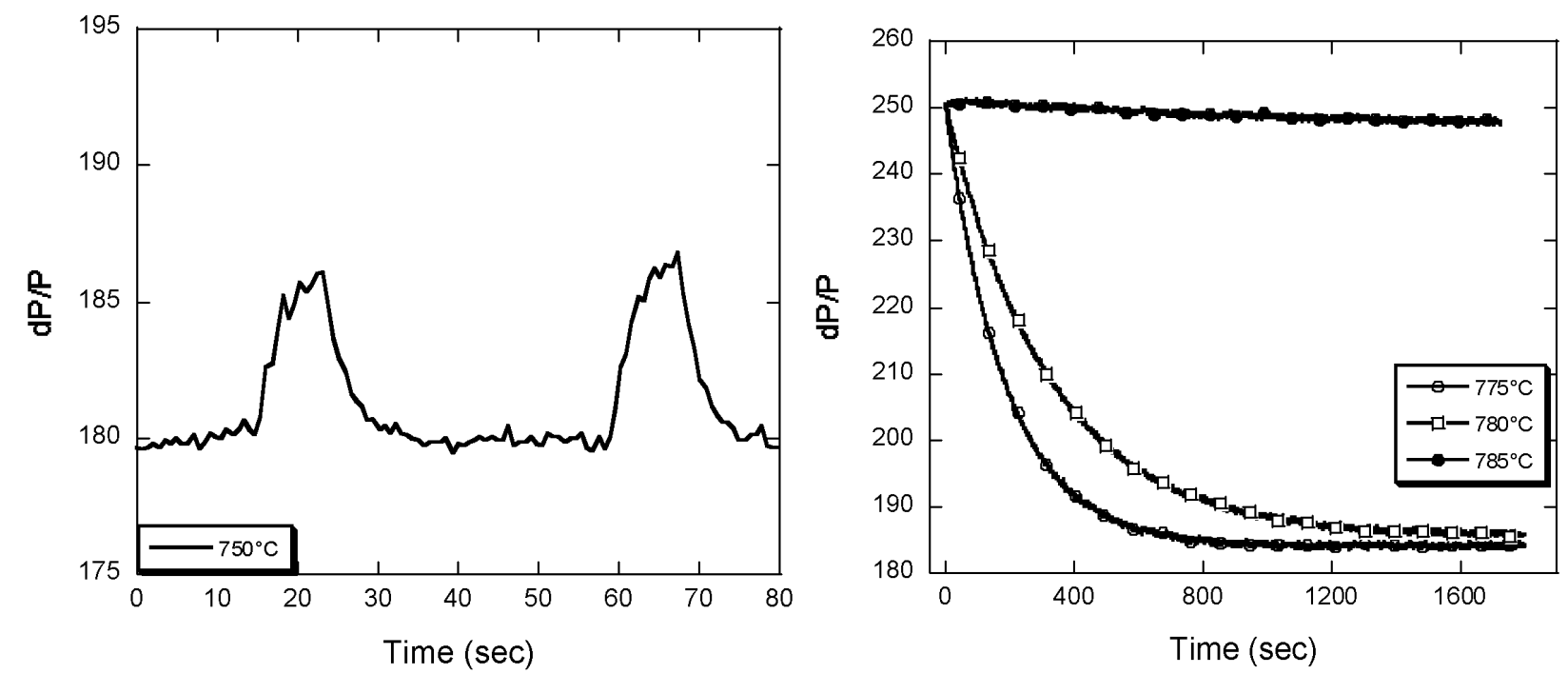

Figure 11. Air leakage through porous LTCC at $750^{\circ} \mathrm{C}$ (left) and evaluation of open porosity-elimination at 775,780 and $785^{\circ} \mathrm{C}$.

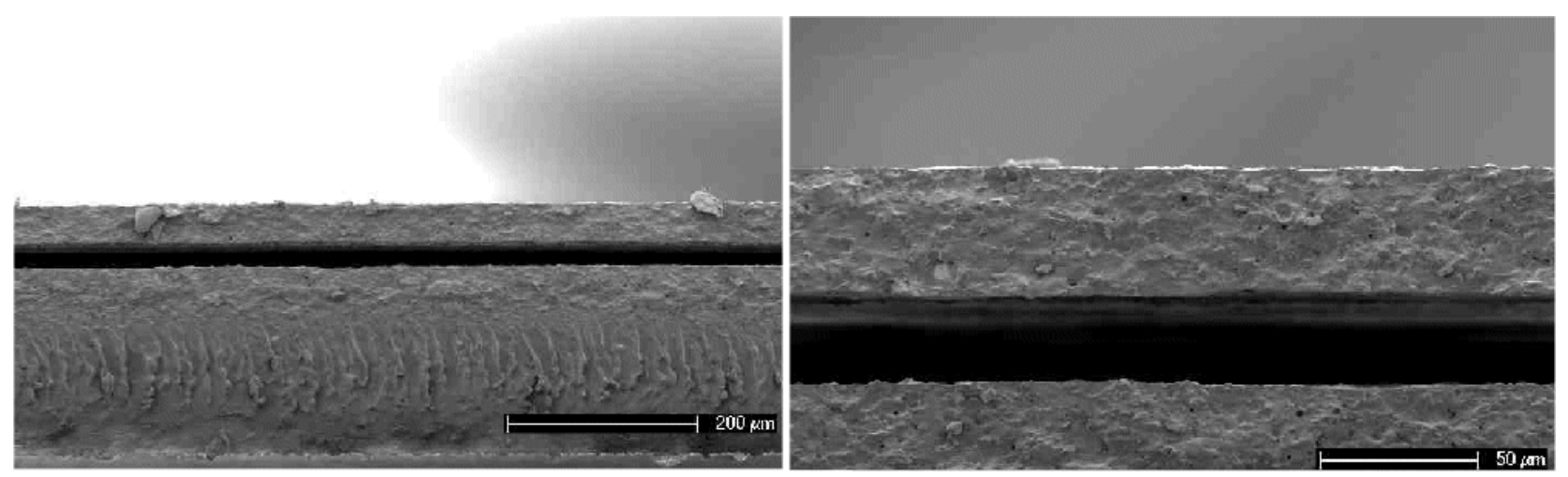

Figure 12. A flat, $18 \mathrm{~mm}$-diameter membrane with $28 \mu \mathrm{m}$ spacing, produced by using CG-based sacrificial paste. 

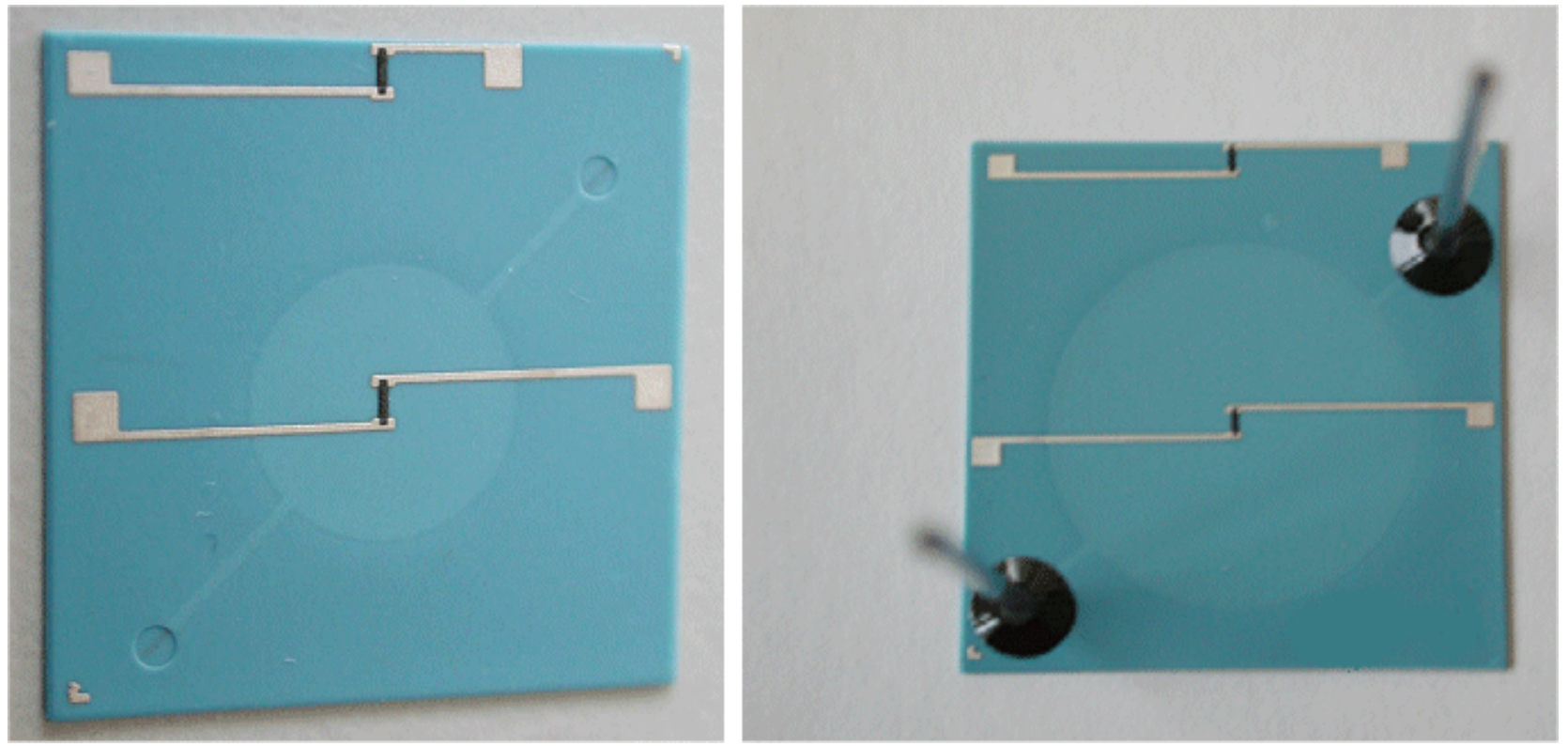

Figure 13. LTCC-based microfluidic sensor fabricated using graphite powder-based sacrificial paste. 